\title{
Effect of temperature on fatigue life behaviour of aluminium alloy AA6061 using analytical approach
}

\author{
F. Hussain ${ }^{1}$, S. Abdullah² and M.Z. Nuawi \\ Department of Mechanical and Materials Engineering, \\ Universiti Kebangsaan Malaysia, \\ 43600 Bangi, Selangor, MALAYSIA \\ ${ }^{1}$ Email: fahad@siswa.ukm.edu.my \\ ${ }^{2}$ Email: shahrum@ukm.edu.my
}

\begin{abstract}
This paper presents the effect of temperature on the fatigue life behaviour of aluminium alloy AA6061, under constant loading conditions, by using an analytical approach. Most of the moving components in automotive engines are under the combined effects of fatigue and temperature. Fatigue life predictions by using conventional experimental methods take a significantly long time. The finite element analysis (FEA) was used for the prediction of fatigue life and point for fatigue failure in the aluminium alloy AA6061 specimen. The stress-life curves at different levels of elevated temperature $(50,100,150$, 200,250 , and $300^{\circ} \mathrm{C}$ ) were predicted by using a mathematical approach of linear interpolation. The maximum temperature of $300^{\circ} \mathrm{C}$ was chosen based on the extreme temperature on a piston face that can be reached during the operation of the engine. The results for fatigue life at ambient temperature and at elevated temperature were compared by the Basquin relation and a decrease of $99 \%$ in fatigue life cycles was found at $300^{\circ} \mathrm{C}$. A general mathematical expression was obtained to calculate the fatigue life for aluminium alloy, AA6061, at elevated temperatures. Therefore, it was concluded that the mathematical expression used in this study can be used as a good alternative approach for time consuming experimental methods. Hence, the mathematical expression proposed in this paper can be used for the early prediction of fatigue life at elevated temperatures without using much experimental analysis.
\end{abstract}

Keywords: Aluminium alloy 6061, elevated temperatures, finite element analysis, fatigue life, linear interpolation.

\section{INTRODUCTION}

Light weight, excellent weldability, and better corrosion resistance are some of the properties of aluminium that result in a rapid increase of aluminium alloys in automotive structural applications [1, 2]. As a good alternative to steel, aluminium can improve the fuel consumption of vehicles by making the cars lightweight [3]. However, in automotive engine components, materials having high fatigue strength at elevated temperatures are needed [4-7]. Cylinder head, piston, engine oil pan, and heat exchanger are some of the examples of the high-temperature automotive engine components made of aluminium alloys [8]. Generally, the fatigue life of a material decreases with increased temperature [9]. The Finite Element Analysis (FEA) can be used as a good alternative to slow timeconsuming experimental work for fatigue life predictions [10-12]. The mathematical 
approach of linear interpolation is useful for the prediction of data points, which contribute in decreasing the time for conducting experiments. There is a decrease in fatigue strength under constant fatigue loading at elevated temperatures as compared to the ambient temperature [13]. This phenomenon of a decrease in fatigue life at elevated temperatures can be studied by comparing the stress-life $(S-N)$ curves at different temperature levels. The stress-life method is a conventional method, but still most widely used to study the fatigue behaviour of a material. In this method, the fatigue life of a material is calculated under different levels of applied stress by plotting a curve known as stress-life or $S-N$ curve. Most of the time, the $S-N$ curve is obtained by experimental analysis [14]. Advances in information technology have made it possible to predict the critical areas for fatigue damage through finite element analysis. Hence, the $S-N$ curve can be obtained using the results from the finite element analysis software [15]. The fatigue life of aluminium alloy wheels by using the stress-life approach has been predicted by simulation by a group of researchers. A decrease of $96 \%$ in the fatigue life of aluminium alloy AA6110 has been found experimentally at $250^{\circ} \mathrm{C}$ (Juijerm \& Altenberger, 2007). A decrease of $80 \%$ in fatigue life at the temperature of $250^{\circ} \mathrm{C}$ for aluminium alloy AA6061 has been reported [16]. Fatigue at elevated temperatures produces large strain deformation, assists in the crack-initiation process, and accelerates the crack propagation rate. Crack initiation occurs earlier at elevated temperatures. The crack growth rates at elevated temperatures are considerably higher than those at ambient temperatures [17].

This study presents the effect of temperature on the stress-life behaviour of aluminium alloy AA6061 under constant loading conditions using a mathematical approach. A medium strength aluminium alloy AA6061 was selected for this study based on its practical applications and good mechanical properties, like its ability to be easily cast, extruded, rolled, machined, etc. This alloy offers good resistance to corrosion. The increase in temperature significantly decreases the fatigue life of aluminium alloys. Conventional experimental methods for the fatigue analysis at elevated temperatures are quite slow. Hence, the FEA approach was used to obtain a stress-life curve at ambient temperatures to save time for running the experiments. The Basquin equation was used to obtain stress-life curves. For the prediction of stress-life curves at elevated temperatures, a mathematical concept of linear interpolation was used. The effect of temperature on the fatigue life of aluminium alloy AA6061 was studied and it was expected that it would be possible to obtain a general mathematical expression to predict the fatigue life of that particular alloy at any elevated temperature, which was the main objective of this paper.

\section{METHODS AND MATERIALS}

Structural or engineering components made of different materials are commonly subjected to the cyclic or fluctuating stress in service. Most of the running parts of automotive engines are under the effect of fatigue and high temperature at the same time. At elevated temperatures, the material behaviour is quite different under cyclic loading as compared to the behaviour at ambient temperatures [18]. The major methods that can be used to predict the fatigue life are strain-life, stress-life, and fracture mechanics. The stress-life curve is useful for providing the fatigue data for the estimation of the number of cycles to failure of the material at a certain level of applied stress [19]. The stress-life curve for constant amplitude loading is plotted on a semi-log or log-log scale. The $S-N$ 
curves were developed by curve fitting on the tabular data using the Basquin equation [14], which can be stated as follows:

$$
\sigma_{a}=A\left(N_{f}\right)^{B}
$$

where, $\sigma_{a}$ is the stress amplitude, $A$ is the fatigue strength coefficient, $N_{f}$ is the number of fatigue cycles, and $B$ is the Basquin exponent.

The Basquin equation was used to obtain a general mathematical relationship to study the stress-life behaviour at elevated temperatures [9]. The equation can be stated as follows:

$$
\sigma_{a}=A\left(N_{f}\right)^{B} T^{c}
$$

where, $T$ is the absolute temperature in kelvin, and $c$ is the temperature sensitivity parameter.

Interpolation is a mathematical way of obtaining the value of an unknown data point based on the values of known surrounding data points. Linear interpolation is a simple way of interpolation that assumes a straight line (linear) relationship between the known points. In simple words, it can be described as an average of two rates over the interpolation period [20]. For a two-dimensional plane with any two points, the coordinates are $\left(x_{1}, y_{1}\right)$ and $\left(x_{2}, y_{2}\right)$. Any unknown point $x$ can be obtained for a given value of $y$, using the concept of linear interpolation, which can be stated as follows:

$$
\frac{y-y_{1}}{y_{2}-y_{1}}=\frac{x-x_{1}}{x_{2}-x_{1}}
$$

In this study, the material used was aluminium wrought alloy AA6061. The standard chemical composition of AA6061 is given in Table 1.

Table 1. Chemical composition of aluminium alloy AA6061 (wt. \%) [16].

\begin{tabular}{lllllllll}
\hline $\mathrm{Mg}$ & $\mathrm{Si}$ & $\mathrm{Mn}$ & $\mathrm{Fe}$ & $\mathrm{Cr}$ & $\mathrm{Zn}$ & $\mathrm{Ti}$ & $\mathrm{Cu}$ & $\mathrm{Al}$. \\
\hline $0.8-1.2$ & $0.4-0.8$ & 0.15 & 0.7 & $0.04-0.35$ & 0.25 & 0.15 & $0.15-0.40$ & Bal. \\
\hline
\end{tabular}

Monotonic tensile tests were performed at room temperature using the Zwick $100 \mathrm{kN}$ servo hydraulic test system with a computer control. The tests were performed according to ASTM: standard E08-11, to obtain the mechanical properties such as yield strength, ultimate tensile strength, and elastic modulus of the material [21]. The specimen for tensile testing is shown in Figure 1. The finite element analysis was used for the fatigue analysis. The commercial simulation software was used for analysis. To initiate the finite element analysis, a 3D CAD model of the specimen was drawn using the commercial CAD software according to ASTM: E466-07, as shown in Figure 2(a). Thereafter, the CAD model was exported to the simulation software as a finite element model. In the software, the required properties such as material properties, applied loading, and constraint information were assigned. Then, a mesh model was obtained using 10 nodes tetrahedral meshing. This produces a high-quality meshing for the boundary representation of the solid model imported from the CAD software [22]. As a result of meshing 6,810 nodes and 4,073 elements were obtained. 


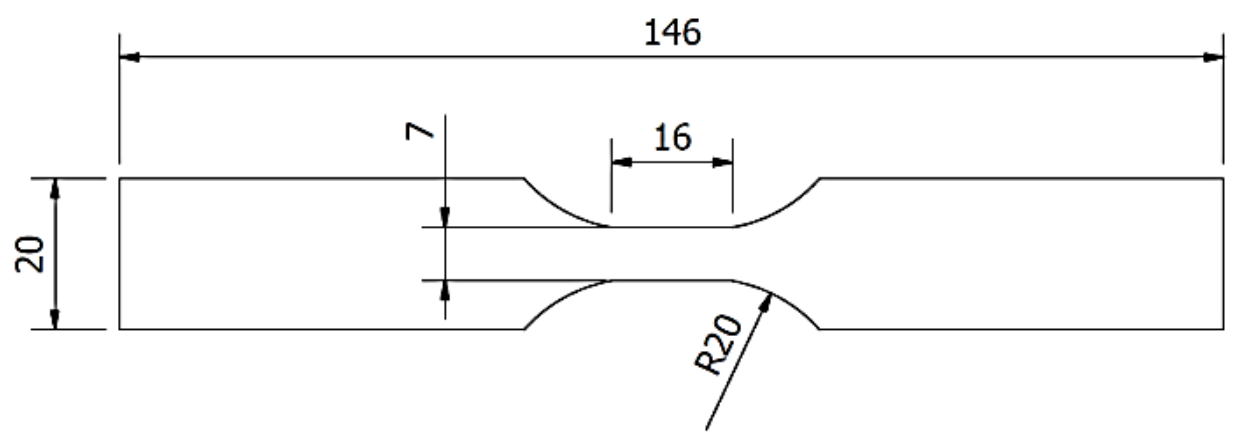

(a)

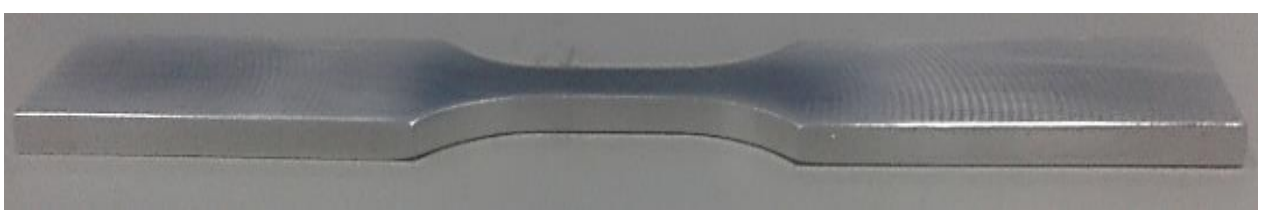

(b)

Figure 1. Specimen for tensile testing: (a) specimen geometry (unit in mm), (b) actual machined specimen.

The mesh model is shown in Figure 2(b). In the next stage, the load and boundary conditions were applied. The one end of the specimen was kept fixed as the equipment used for fatigue testing is uniaxial with one end fixed. On the other end, the load was applied as shown in Figure 3. The fatigue load was applied as fully reversed using stress ratio $(R=-1)$. The fatigue load was applied in the CAD model as force starting from $90 \%$ of UTS of AA6061 until the fatigue limit was reached. The mechanical properties used for the finite element analysis are shown in Table 2.
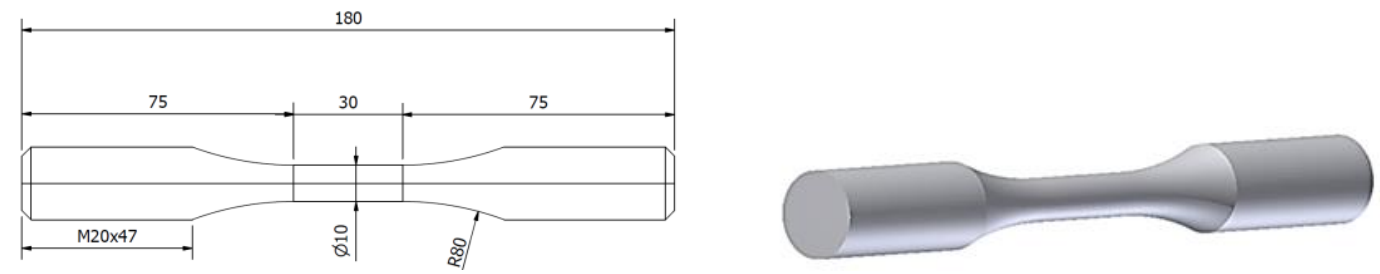

(a)

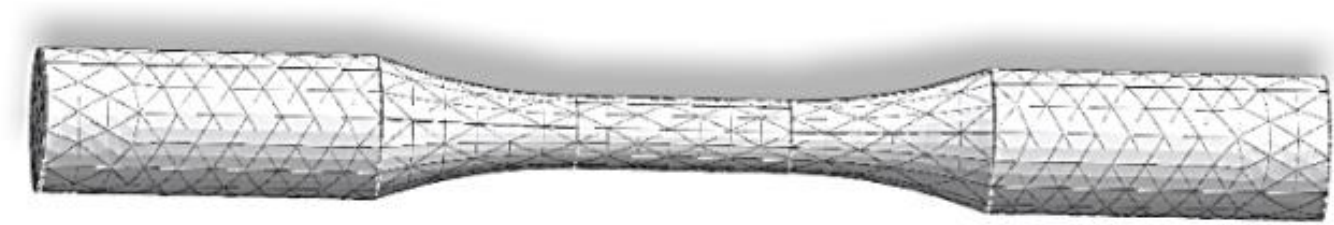

(b)

Figure 2. Specimen for fatigue simulation: (a) 3D CAD model, and specimen, dimensions in millimetres ( $\mathrm{mm}$ ); (b) model after meshing. 
The fatigue analysis was performed using the stress-life approach by the commercial simulation software. Using the simulation results, the stress-life curve was obtained at ambient temperature. An experimental fatigue analysis was performed using a $100 \mathrm{kN}$ servo-hydraulic fatigue testing machine, according to the ASTM: E466-07 standard. The tests were conducted using the same parameters as the FEA analysis.
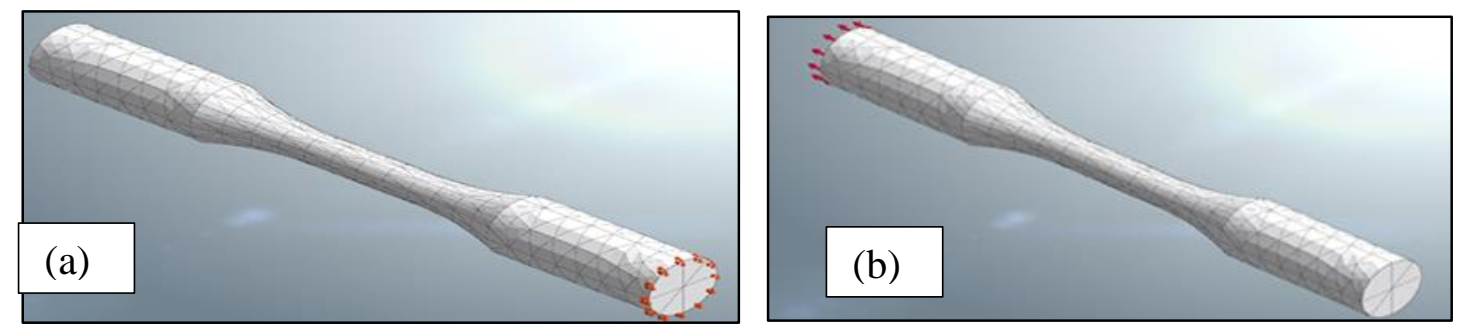

Figure 3. Constraints and boundary conditions: (a) fixed end, (b) application of force.

Table 2. Mechanical properties of aluminium alloy 6061 (Wong, 1984) used in FEA.

\begin{tabular}{ll}
\hline Mechanical properties & AA6061 \\
\hline Monotonic properties & \\
Ultimate tensile strength, $\sigma_{u}(\mathrm{MPa})$ & 283 \\
Yield strength, $\sigma_{y}(\mathrm{MPa})$ & 265 \\
Modulus of elasticity, $E(\mathrm{GPa})$ & 64 \\
Strength coefficient, $K(\mathrm{MPa})$ & 416 \\
Strain hardening exponent, $n$ & 0.079 \\
Cyclic and Fatigue properties & \\
Fatigue strength exponent, $B$ & -0.092 \\
Fatigue ductility coefficient, $\varepsilon_{f}^{\prime}$ & 1.34 \\
Fatigue ductility exponent, $c$ & -0.83 \\
Cyclic strength coefficient, $K^{\prime}$ & 426 \\
Cyclic strain hardening exponent, $n$ & 0.062 \\
\hline
\end{tabular}

\section{RESULTS AND DISCUSSION}

The tensile tests of aluminium alloy AA6061 specimen show a tensile strength of 283 $\mathrm{MPa}$, the yield strength of $265 \mathrm{MPa}$, and an elastic modulus of $64 \mathrm{GPa}$. The values for these mechanical properties are slightly lower but quite close to the standard values [23]. There is a difference of $8.7 \%$ in tensile strength, 3.6\% in yield strength, and $7.2 \%$ in elastic modulus between the standard and experimental values. These properties were compared with the standard as shown in Table 3. This difference can be attributed to the differences in production and manufacturing processes [24]. These properties were useful for the determination of material characteristics, alloy development, and design under certain conditions. The stress-strain curve obtained for the aluminium alloy AA 6061 is shown in Figure 4. The fatigue analysis by using the stress-life approach in the finite element analysis software was used to obtain the number of cycles to failure and fatigue damage values at different levels of applied stress. The point for maximum fatigue damage was obtained and it is shown in Figure 5(a). 
Table 3. Mechanical properties obtained from monotonic tensile testing.

\begin{tabular}{llll}
\hline $\begin{array}{l}\text { Aluminium } \\
\text { AA6061 }\end{array}$ & $\begin{array}{l}\text { Tensile strength } \\
\sigma_{\mathrm{u}}(\mathrm{MPa})\end{array}$ & $\begin{array}{l}\text { Yield strength } \\
\sigma_{\mathrm{y}}(\mathrm{MPa})\end{array}$ & $\begin{array}{l}\text { Elastic modulus } \\
E(\mathrm{GPa})\end{array}$ \\
\hline $\begin{array}{l}\text { Experimental } \\
\text { values }\end{array}$ & 283 & 265 & 64 \\
Standard values & 310 & & \\
Difference $(\%)$ & 8.7 & 275 & 69 \\
\hline
\end{tabular}

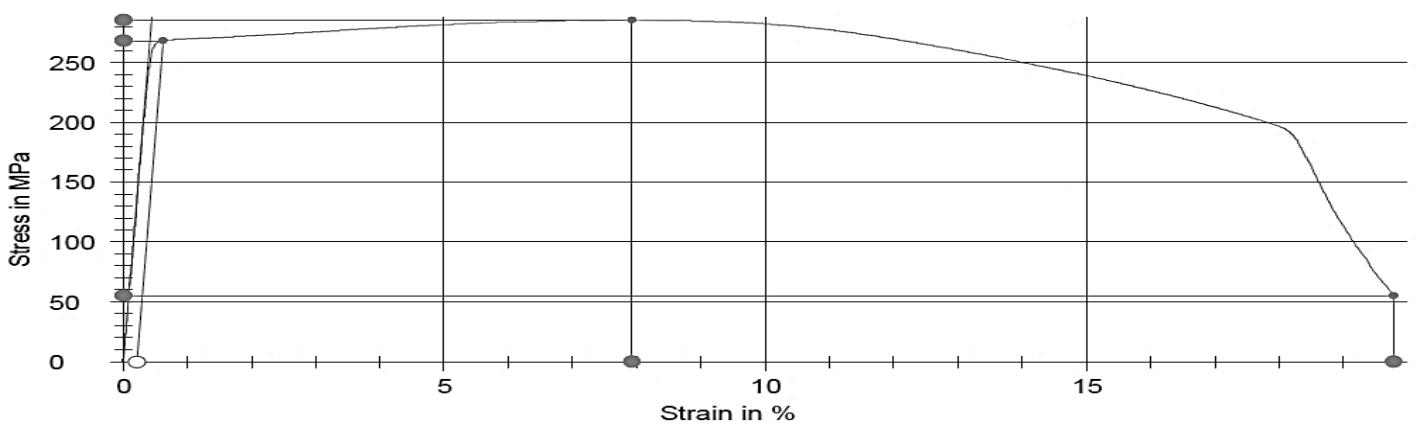

Figure 4. Stress strain $(\sigma \varepsilon)$ curve for AA 6061 obtained from the tensile testing.

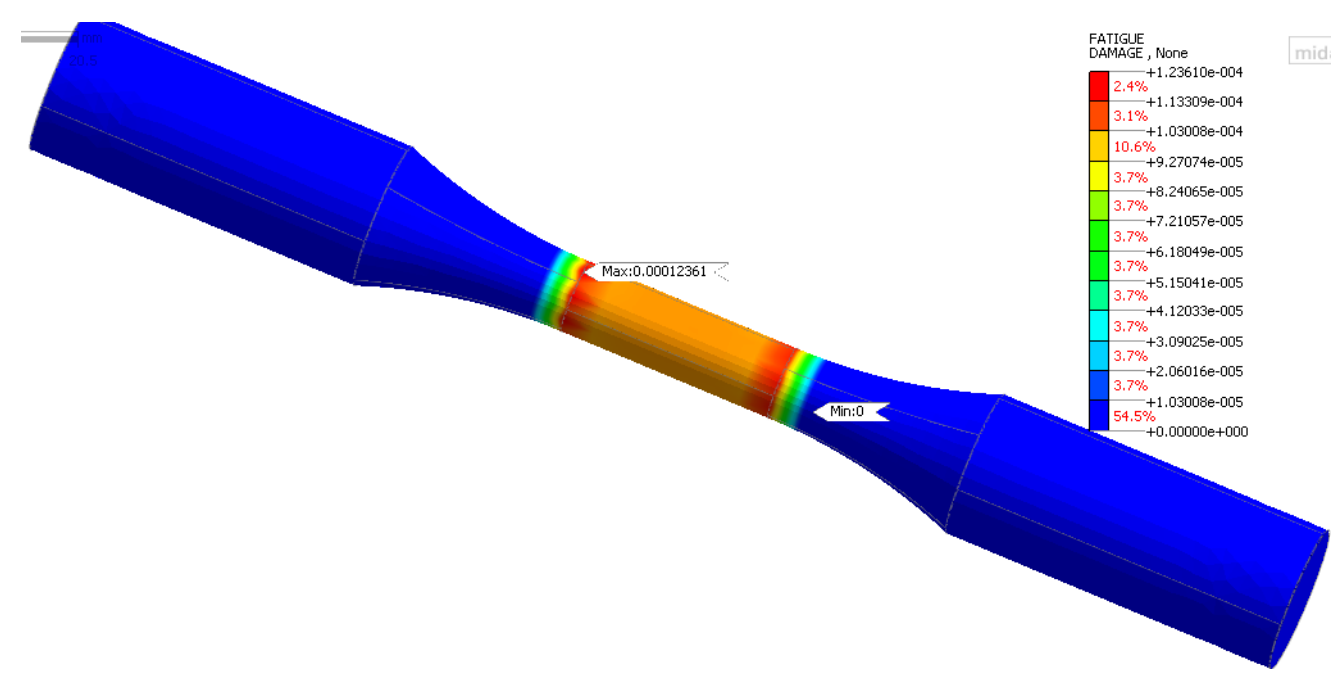

(a)

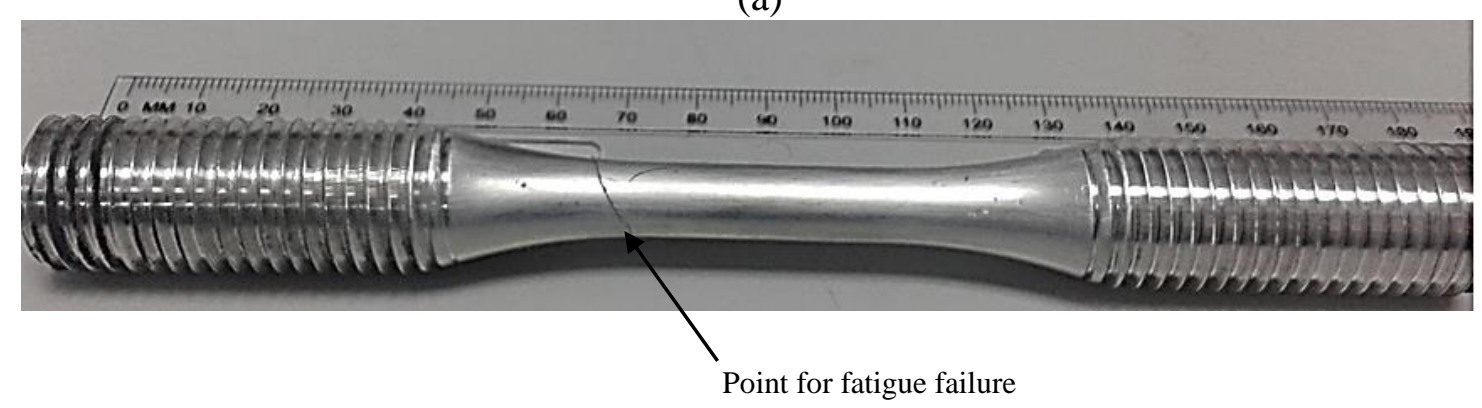

(b)

Figure 5. Point for fatigue failure in AA6061 specimen: (a) predicted by FEA analysis; (b) obtained from experiment. 
The point for fatigue damage that was predicted by the finite element analysis software is helpful to obtain the most critical points in the aluminium alloy AA6061 specimen [16]. The same point for fatigue failure was obtained from the experimental fatigue analysis as predicted by the FEA analysis and shown in Figure 4(b). The number of cycles to failure was obtained by the finite element analysis at ambient temperature. The results were plotted on a log-log scale to obtain a stress-life curve at ambient temperature as represented by Equation (4) below:

$$
\sigma_{a}=651.8\left(N_{f}\right)^{-0.092}
$$

where $\sigma_{a}$ is the applied stress and $N_{f}$ is the number of cycles to failure. This equation shows the value of $651.8 \mathrm{MPa}$ and $-0.092 \mathrm{MPa}$ for the fatigue strength coefficient $A$ and Basquin exponent $B$, respectively.

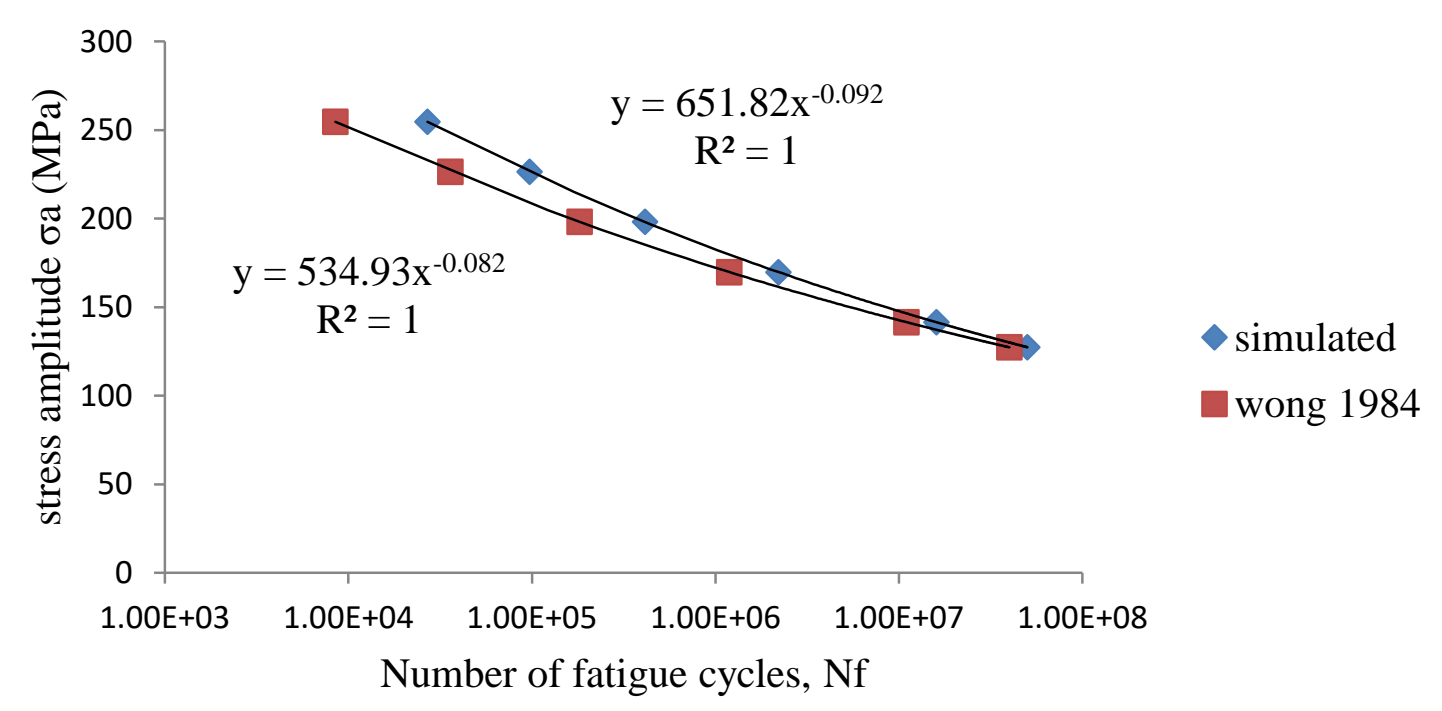

Figure 6. Comparison between the simulated and standard stress-life curves for AA6061.

The previous study shows that the values for fatigue strength coefficient $A$ and Basquin exponent $B$ are $535 \mathrm{MPa}$ and -0.082 , respectively [25]. There is a difference of $17 \%$ in fatigue strength coefficient and $11 \%$ in Basquin exponent. This difference is mainly due to the difference in mechanical properties of the alloy used for simulation and those used for the previous experimental study. There was a difference of $7-10 \%$ in the monotonic tensile properties. The comparison between the stress-life curves obtained from the finite element analysis, calculated based on the values obtained from the previous study, is shown in Figure 6. The value of fatigue strength coefficient at room temperature was of great importance [14]. Fatigue strength coefficient is a material constant, but it changes with temperature [9]. A decrease of $28 \%$ in the fatigue strength coefficient of aluminium AA 6061 at a temperature of $250^{\circ} \mathrm{C}$ has been found experimentally [26]. Assuming the similar trend in fatigue strength coefficient, its value at different levels of elevated temperatures $\left(50,100,150,200,300^{\circ} \mathrm{C}\right)$ were obtained by using a mathematical approach of linear interpolation, as shown in Equation (3). The linear interpolation was used due to the lack of ability of most of the commercial FEA simulation software to perform the fatigue analysis at elevated temperatures. The 
predicted stress-life curves at different levels of elevated temperatures are shown in Figure 7. There is no study in the authour's knowlodge in which the effect of temperature on the fatigue life of AA6061 has been studied until the elevated temperature range of $300^{\circ} \mathrm{C}$.

Table 4. Value of fatigue strength coefficient $A$ at different temperatures.

\begin{tabular}{llllllll}
\hline Temperature $\left({ }^{\circ} \mathrm{C}\right)$ & 27 & 50 & 100 & 150 & 200 & 250 & 300 \\
\hline $\begin{array}{l}\text { Fatigue strength } \\
\text { coefficient, } A(\mathrm{MPa})\end{array}$ & 651.8 & 632.87 & 591.73 & 550.60 & 509.44 & 468.3 & 427.93 \\
\hline
\end{tabular}

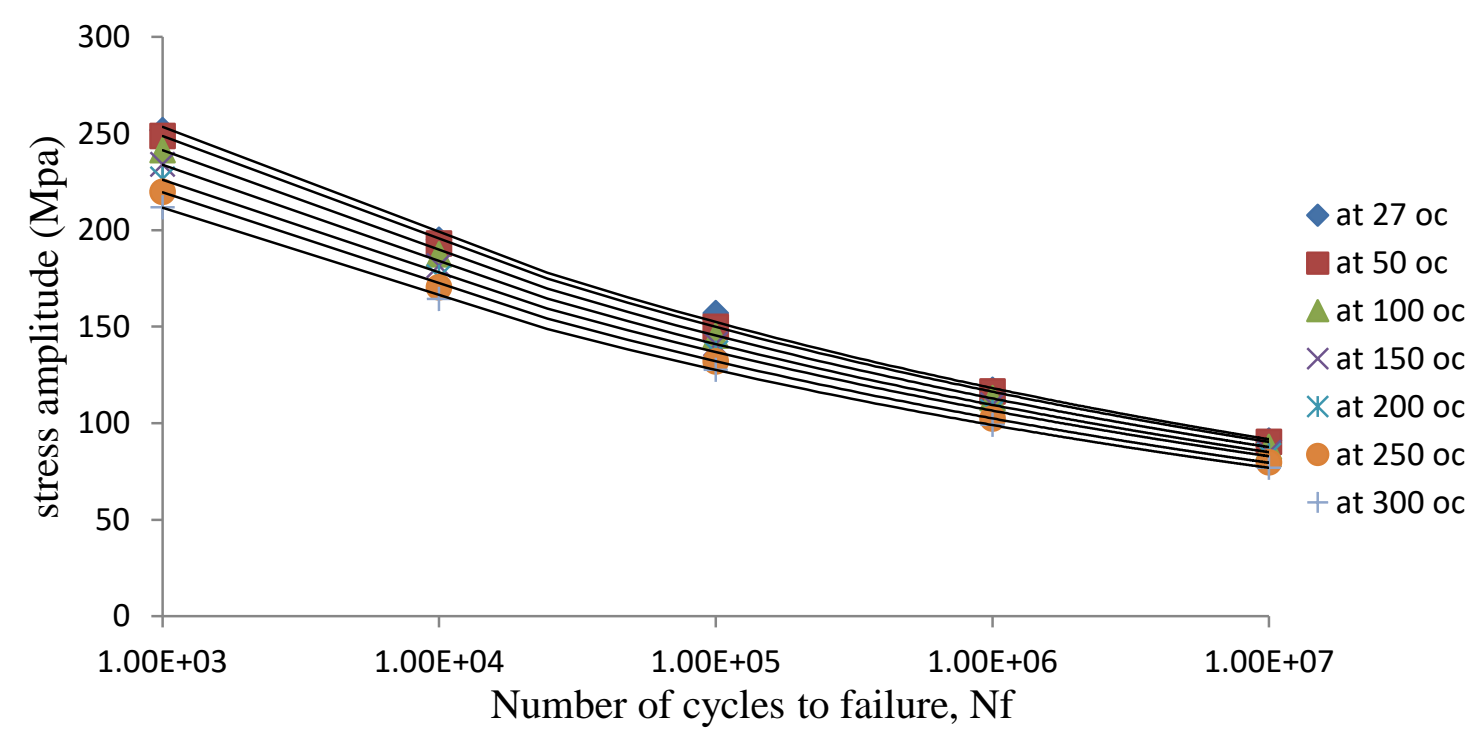

Figure 7 . Stress- life curves at different levels of elevated temperature.

These curves show a decrease in fatigue life with the increase in temperature for aluminium alloy AA6061. There is a considerable decrease in fatigue life with the increase in temperature. The main factors that account for this decrease are the increase in the rate of oxidation at elevated temperatures and the decline in monotonic mechanical properties with temperature [16].

Figure 8 shows the decrease in the number of cycles to failure with the increase in temperature. Many factors caused a decrease in fatigue life with an increase in temperature. Out of these, the main factor is that the temperature increase can accelerate the rate of oxidation, causing the irreversibility of cyclic slip, and as a result, it damages the microstructure. The variation of temperature also affects the material properties like elastic modulus and shear modulus [27]. There is a considerable decrease in the strength of the material with an increase in temperature, which can be found by tensile tests at increased temperatures [17]. Therefore, both the microstructural and mechanical behaviours in materials contribute significantly in crack initiation and propagation, which ultimately affects the total fatigue life [14].

$$
N_{f}=170624 e^{-0.017 T}
$$


Equation (2) is applied to obtain a mathematical relationship for the stress-life behaviour of aluminium alloy AA 6061 at elevated temperatures. The temperature sensitivity parameter, $c$, in Equation (2) is obtained by substituting the values of $A$ and $B$ acquired from Equation (4), $N_{f}$ from Equation (5) at different values of elevated temperatures, and absolute temperature in kelvin.

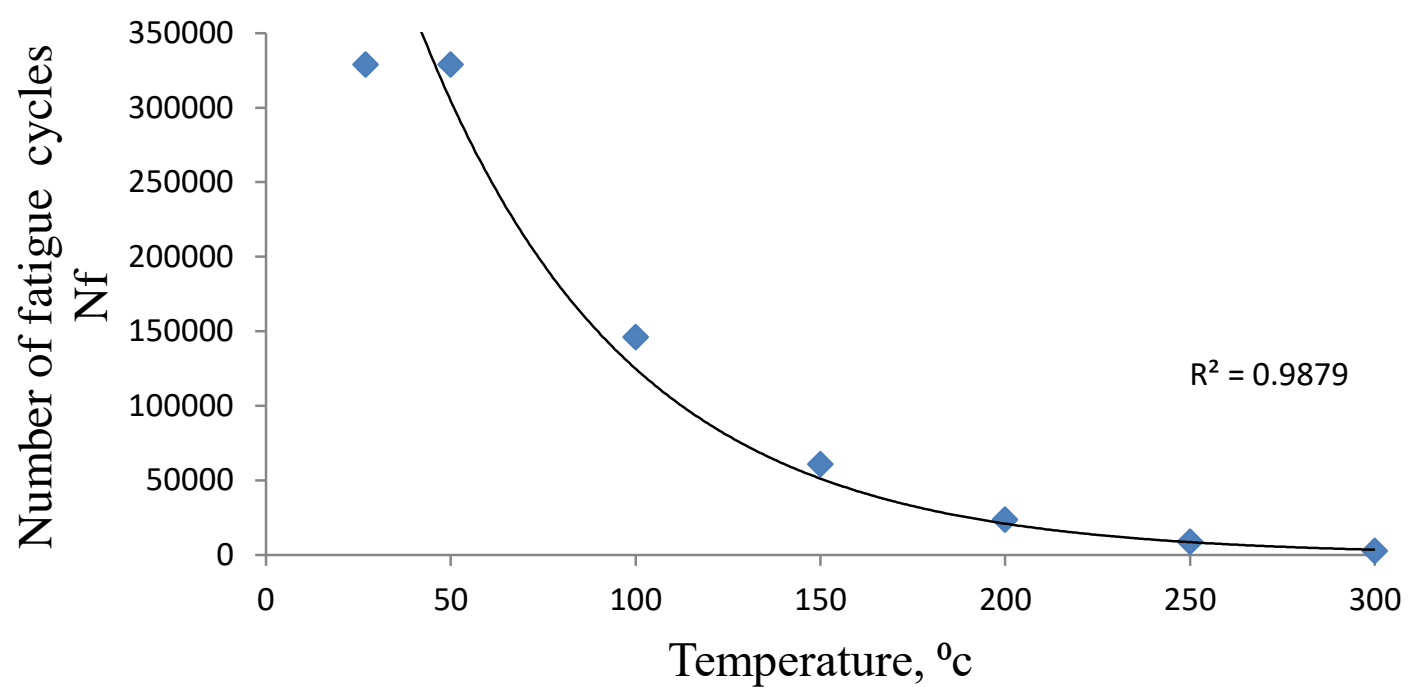

Figure 8. The effect of temperature on the fatigue life of aluminium alloy AA6061.

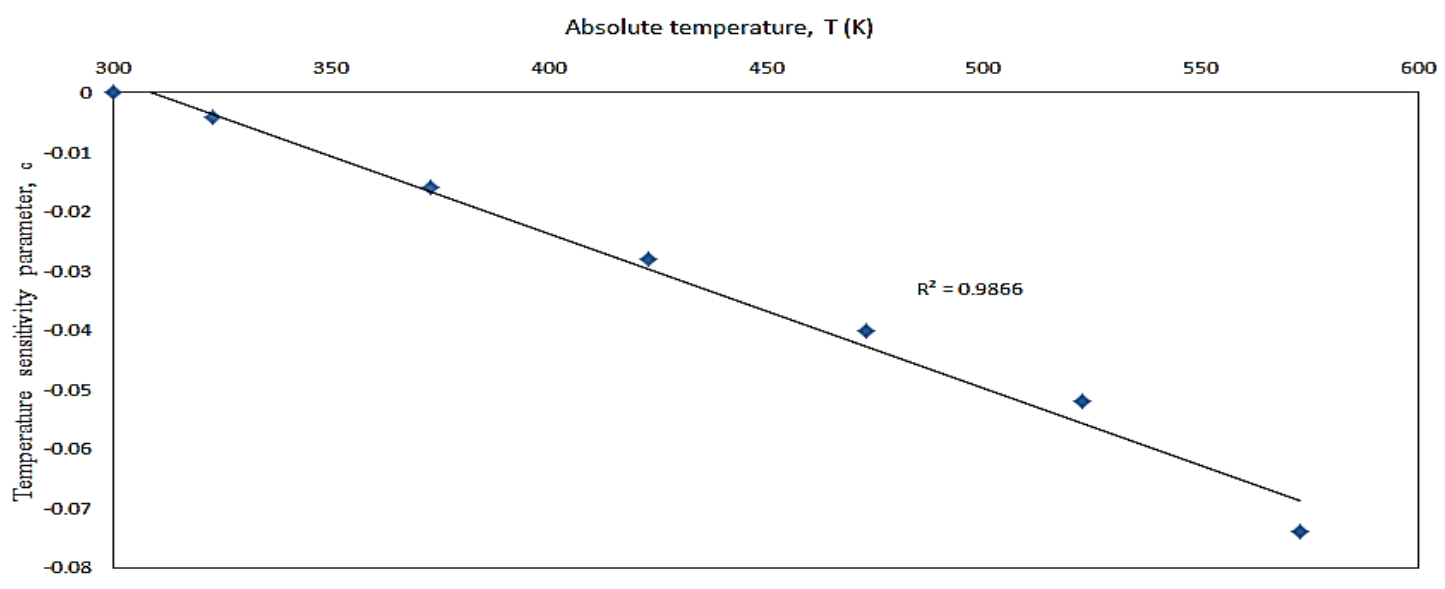

Figure 9. The relationship between temperature sensitivity parameter and the absolute temperature of the aluminum alloy AA6061.

$$
c=-0.0003 T+0.0805
$$

Equation (6) shows a linear relationship between the temperature sensitivity parameter, $c$ and the absolute temperature, $T$. A mathematical relationship was obtained to find the number of cycles to failure at any level of applied stress at $300^{\circ} \mathrm{C}$ as shown by Eq. (7): 


$$
N_{f}=\left(\frac{\sigma_{a}}{427.93}\right)^{-\frac{1}{0.092}}
$$

A mathematical relationship was obtained to calculate the number of fatigue cycles at any level of applied stress and at any temperature as stated in Eq. (8):

$$
N_{f}=\left(\frac{\sigma_{a}}{651.8 T^{c}}\right)^{-\frac{1}{0.092}}
$$

By using Eq. (8), the number of fatigue cycles for any stress level at any value of elevated temperatures can be calculated. For example, at ambient temperature, the fatigue life at the stress amplitude of $200 \mathrm{MPa}$ was calculated to be 377,770 cycles, which were reduced to approximately 3,900 cycles at the temperature of $300^{\circ} \mathrm{C}$. Hence, a decline of $99 \%$ was observed. A decrease of $80 \%$ in fatigue life has been experimentally observed at the temperature of $250^{\circ} \mathrm{C}$ for the aluminium alloy AA6061.

\section{CONCLUSIONS}

In this paper, an analytical approach was used to study the effect of temperature on the fatigue life behaviour of aluminium alloy AA 6061. The fatigue life study at elevated temperature shows that the number of cycles to failure was significantly affected by temperature. The use of the FEA simulation and mathematical approach of linear interpolation as an alternative to experimental work significantly decreases the time for analysis. Due to less weight, good mechanical properties, and better corrosion resistance, aluminium alloy AA6061 finds good use at ambient temperature environments. Comparing the fatigue life at $300^{\circ} \mathrm{C}$ with ambient temperature, it was observed that the number of cycles to failure was reduced as much as $99 \%$. This large decline in a number of cycles to failure limits the use of aluminium alloy AA6061 in elevated temperature environments. There are no previous reports, to the best of the author's knowledge that show the effect of temperature up to $300^{\circ} \mathrm{C}$ on the fatigue life for a particular alloy. Most of the operational parts in an automotive engine are under the effect of fatigue at elevated temperatures. This study revealed that aluminium alloy AA6061 is unsuitable for hightemperature automotive engine parts.

\section{ACKNOWLEDGEMENTS}

The authors would like to thank Universiti Kebangsaan Malaysia for providing facilities to do experimental work and to run the simulation.

\section{REFRENCES}

[1] Mo DF, Guo-Qiu H, Zheng-Fei H, Zheng-Yu Z, Cheng-Shu C, Wei-Hua Z. Crack initiation and propagation of cast A356 aluminum alloy under multi-axial cyclic loadings. International Journal of Fatigue. 2008;30:1843-50.

[2] Maleque MA, Radhi M, Rahman MM. Wear study of Mg-SiCp reinforcement aluminium metal matrix composite. Journal of Mechanical Engineering and Sciences. 2016;10:1758-64. 
[3] Hadley S, Das S, Miller J. Aluminum R\&D for automotive uses and the department of energy's role. ORNL/TM-1999/157, Oak Ridge National Laboratory, Oak Ridge, Tenn. 2000.

[4] Silva F. Fatigue on engine pistons-A compendium of case studies. Engineering Failure Analysis. 2006;13:480-92.

[5] Sivananth V, Vijayarangan S. Fatigue Life Analysis and Optimization of a Passenger Car Steering Knuckle under Operating Conditions. International Journal of Automotive and Mechanical Engineering. 2015;11:2417-29.

[6] Kamal M, Rahman MM. Fatigue Life Estimation Based on Continuum Mechanics Theory with Application of Genetic Algorithm. International Journal of Automotive and Mechanical Engineering. 2015;11:2686-98.

[7] Kamal M, Rahman MM. Dual-Criteria Method for Determining Critical Plane Orientation for Multiaxial Fatigue Prediction Using a Genetic Algorithm. International Journal of Automotive and Mechanical Engineering. 2015;11:257181.

[8] Zhu X, Shyam A, Jones J, Mayer H, Lasecki J, Allison J. Effects of microstructure and temperature on fatigue behavior of E319-T7 cast aluminum alloy in very long life cycles. International Journal of Fatigue. 2006;28:1566-71.

[9] Juijerm P, Altenberger I. Effect of temperature on cyclic deformation behavior and residual stress relaxation of deep rolled under-aged aluminium alloy AA6110. Materials Science and Engineering: A. 2007;452:475-82.

[10] Joun M, Choi I, Eom J, Lee M. Finite element analysis of tensile testing with emphasis on necking. Computational Materials Science. 2007;41:63-9.

[11] Mohamed MA, Manurung YHP, Ghazali FA, Karim AA. Finite Element-Based Fatigue Life Prediction of a Load-Carrying Cruciform Joint. Journal of Mechanical Engineering and Sciences. 2015;8:1414-25.

[12] Kamal M, Rahman MM. An Integrated Approach for Fatigue Life Estimation Based on Continuum Mechanics Theory and Genetic Algorithm. International Journal of Automotive and Mechanical Engineering. 2015;11:2756-70.

[13] Lee YL, Pan J, Hathaway R, Barkey M. Fatigue Testing and Analysis: Theory and Practice: Butterworth-Heinemann; 2011.

[14] Liu Y, Yu J, Xu Y, Sun X, Guan H, Hu Z. High cycle fatigue behavior of a single crystal superalloy at elevated temperatures. Materials Science and Engineering: A. 2007;454:357-66.

[15] Beden S, Abdullah S, Ariffin A, Al-Asady N. Fatigue crack growth simulation of aluminium alloy under spectrum loadings. Materials \& Design. 2010;31:3449-56.

[16] Zakaria KA, Abdullah S, Ghazali MJ. Comparative study of fatigue life behaviour of AA6061 and AA7075 alloys under spectrum loadings. Materials \& Design. 2013;49:48-57.

[17] Uematsu Y, Akita M, Nakajima M, Tokaji K. Effect of temperature on high cycle fatigue behaviour in $18 \mathrm{Cr}-2 \mathrm{Mo}$ ferritic stainless steel. International Journal of Fatigue. 2008;30:642-8.

[18] Bahaideen FB, Saleem AM, RIPIN ZM, Samad Z, Badarulzman NA. Fatigue Behaviour of Aluminum Alloy at Elevated Temperature. Modern Applied Science. 2009;3:p52.

[19] Mohammad M, Abdullah S, Jamaludin N, Innayatullah O. Predicting the fatigue life of the SAE 1045 steel using an empirical Weibull-based model associated to acoustic emission parameters. Materials \& Design (1980-2015). 2014;54:103948. 
[20] Bronstejn IN, \& Semendjaev, K. A. Handbook of mathematics: Springer.; 2013.

[21] Mohammad M, Abdullah S, Jamaluddin N, Padzi M. On the need to correlate acoustic emission and fatigue strain signals associated to metallic component life assessment. International Journal of Mechanical and Materials Engineering. 2012;7:78-82.

[22] Kadhim N, Abdullah S, Ariffin A. Effect of the fatigue data editing technique associated with finite element analysis on the component fatigue design period. Materials \& Design. 2011;32:1020-30.

[23] Boyer H, Gall T. Metals HandbookAmerican Society for Metals. Metals Park, OH. 1985:216.

[24] Ribeiro AS, de Jesus AM, Feup I. Fatigue behaviour of welded joints made of 6061-T651 aluminium alloy: INTECH Open Access Publisher; 2011.

[25] Wong WA. Monotonic and cyclic fatigue properties of automotive aluminum alloys. SAE Technical Paper; 1984.

[26] Zakaria KA, Abdullah S, Ghazali MJ, Azhari CH. Influence of spectrum loading sequences on fatigue life in a high-temperature environment. Engineering Failure Analysis. 2013;30:111-23.

[27] Kwon Y-N, Lee Y, Lee J. Deformation behavior of Al-Mg-Si alloy at the elevated temperature. Journal of Materials Processing Technology. 2007;187:533-6. 